\title{
Anthropometric Assessment of Canthal Distances and Canthal Index of South Indian Region: A Cross-Sectional Study
}

\author{
Radha K. ${ }^{1}$, Srinivasan K.R. ${ }^{2}$ \\ IProfessor, Dept. of Anatomy, Vinayaka Missions Medical College, Karaikal, Puducherry, India-609 609, \\ ${ }^{2}$ Professor Emeritus, Aarupadai Veedu Medical College, Pondicherry, India-607402
}

\begin{abstract}
Background: Orbitofacial anthropometric measurements can be used in identification of gender and ethnicity in forensic anthropology. It also plays a crucial role used in plastic surgery and for identifying genetic syndromes. Canthus is the term employed to explain the either corner of the eyes. Inner canthus is also called as medial or nasal canthus. Outer canthus, is otherwise called as lateral or temporal canthus. Normal canthal values can function as a guide for the diagnosis of pathology and interventions for craniofacial abnormalities. Thus, it is necessary to have a knowledge about the local data of those parameters since this standard reflects the doubtless different pattern of craniofacial growth resulting from racial, ethnic, sexual and dietary differences. Hence this study is undertaken to find out the normative inner canthal and outercanthal distance measurement in population of South Indian region.
\end{abstract}

Aims and Objectives: The present study was done to find out the normal inner and outercanthal distance and also canthal index of population of South Indian ethnic origin and also to analyse the sexual dimorphism in them.

Materials and Method: This descriptive cross-sectional study was conducted on 200 volunteers of age group 18-25 years of both sexes belonging to South Indian region. Innercanthal distance(ICD) and Outer canthal distance(OCD) were measured using digital vernier caliper.Canthal index was calculated. All the data were analysed using SPSS 16.0 version software and correlated with gender.

Results: Mean innercanthal distance was found to be $2.64 \pm 0.51 \mathrm{~cm}$ in males and $2.51 \pm 0.46 \mathrm{~cm}$ in females respectively in the present study. There is significant sexual dimorphism in ICD . The study also showed outercanthal distance to be $10.35 \pm 0.81 \mathrm{~cm}$ in males and $10.19 \pm 1.02 \mathrm{~cm}$ in females respectively. Canthal index was $25.71 \pm 4.91$ in males and $24.83 \pm 7.83$ in females. There is no significant sexual dimorphism in OCD and Canthal index.

Conclusion: It was observed that all the values were significantly higher in males than females of south Indian ethnic origin. And there is a significant sexual dimorphism in inner intercanthal distance.

Keywords: Innercanthal distance, outercanthal distance, orbitofacial anthropometry.

\section{Introduction}

The face is the most appealing and attractive structure in the human body. Orbit, the anatomical entity in the face plays a vital role in determining the facial attractiveness. It also influences the visual judgement of healthy person as well as those with facial deformities ${ }^{[1]}$. Anthropometry which is the branch of anthropology measures human physical dimensions ${ }^{[2]}$. Measurements of soft tissue using a anthropometric instrument is considered as a direct quantitative method to assess physical dimension and the method are non-invasive and easy to perform ${ }^{[3]}$.

Orbitofacial anthropometry has a key role in assessing dysmorphic syndromes, hypertelorism, facial trauma especially naso-orbitoethmoid injury and alsoin diagnosing neural crest anomalies. It also aids in planning reconstructive surgical procedures of face and getting fruitful outcome.

Canthus is the term used to describe the either 
corner of eyes. Inner canthus (medial or nasal canthus) is formed by the medial part of superior and inferior eyelids whereas outer canthus (lateral or temporal canthus)) is formed by the lateral part of superior and inferior eyelids ${ }^{[2]}$. Inner intercanthal distance (ICD) is the distance between medial canthi of eyes and Outer canthal distance (OCD) is the distance between lateral canthi of eyes ${ }^{[4]}$.

Canthal measurements become stable once it has reached the adult level most probably in the mid to late twenties ${ }^{[5]}$. Canthal measurements are influenced by age,sex,race and ethnicity.

Normal values of canthal distance helps and serves as a guide to diagnose the pathologies and for early surgical intervention. Knowledge of subtle morphological changes in Dysmorphic syndromes which were diagnosed based on molecular and cytogenetic techniques will help in directing towards the useful diagnostic test ${ }^{[6]}$.

Knowledge of variation in the morphological and anatomical relationships of periorbital structures among different ethnic groups helps the surgeons to retain the ethnical features and to derive an ideal outcome in the reconstructive and cosmetic surgeries. Hence this study is under taken to find out the normative inner intercanthal and outer-intercanthal distance measurement of people of south Indian ethnic origin.

\section{Materials and Method}

Present study was done with 200 volunteers of south Indian ethnic origin (Males and Females) of age group 19-25 years. Prior to the initiation of study process, approval was obtained from Institutional Ethical Committe, Vinayaka Missions Medical College, Karaikal. Informed,written consent was got from each participant after explaining the study clearly. Those having orbitofacial deformity, facial trauma,any congenital anomalies involving orbitofacial region were excluded from the study.

All the measurements were taken using digital vernier caliper with the subjects sitting straight with eyes closed and in a relaxed state. Intercanthal distance (ICD) was measured from medial canthus of one eye to medial canthus of the other eye. Outercanthal distance (OCD) was taken from lateral canthus of one eye to the lateral canthus of other eye. All measurements were taken in centimetre. Each measurement was taken twice to avoid error and all the measurements were tabulated in a log book.

Canthal index was calculated using the formula

Intercanthal distance/Outercanthal distance $\times 100$

All measurements were analysed using SPSS software 16.0 version. Descriptive variables were depicted as mean and standard deviation. The mean values of the measurements were compared between either sexes using the independent $t$ test.

\section{Results}

The study was done on 90 males and 110 females of age group 18-25 years showed the mean value of innercanthal distance as $2.55 \pm 0.51 \mathrm{~cm}$, the mean value of outercanthal distance as $10.26 \pm 0.92 \mathrm{~cm}$ and mean canthal index was $25.23 \pm 6.71$.(Table 1).

Table I: Descriptive statistics for ICD, OCD, CANTHAL Index

\begin{tabular}{|l|c|c|c|}
\hline Variable & N & Range & Mean \pm SD \\
\hline ICD & 200 & $0.90-4.31$ & $2.55 \pm 0.51$ \\
\hline OCD & 200 & $3.38-12.65$ & $10.26 \pm 0.92$ \\
\hline Canthal Index & 200 & $8.31-81.07$ & $25.23 \pm 6.71$ \\
\hline
\end{tabular}

Table II: Gender with variables Mean \pm sd comparison using independent sample $t$ test

\begin{tabular}{|l|c|c|c|c|c|c|}
\hline \multirow{2}{*}{ Variable } & \multicolumn{2}{|c|}{ Male } & \multicolumn{2}{c|}{ Female } & \multirow{2}{*}{ t } & \multirow{2}{*}{ p value } \\
\cline { 2 - 5 } & $\mathbf{N}(\%)$ & Mean \pm SD & $\mathbf{N}(\%)$ & Mean \pm SD & & 0.008 \\
\hline ICD & $90(45 \%)$ & $2.64 \pm 0.51$ & $110(55 \%)$ & $2.51 \pm 0.46$ & 2.689 & 0.234 \\
\hline OCD & $90(45 \%)$ & $10.35 \pm 0.81$ & $110(55 \%)$ & $10.19 \pm 1.02$ & 1.195 & 0.351 \\
\hline CANTHAL Index & $90(45 \%)$ & $25.71 \pm 4.91$ & $110(55 \%)$ & $24.83 \pm 7.83$ & 0.935 & 0.935 \\
\hline
\end{tabular}

Table II shows the mean value of ICD, OCD and CANTHAL INDEX among males and females. All values are higher in males than females. And there is a significant sexual dimorphism in ICD. 
Table III: Mean values of ICD,OCD And Canthal index of various regions of South India

\begin{tabular}{|l|c|c|c|c|}
\hline State & N & ICD & OCD & Canthal Index \\
\hline Tamilnadu & 132 & $2.46 \pm 0.48$ & $10.21 \pm 1.02$ & $24.7 \pm 7.65$ \\
\hline Kerala & 42 & $2.68 \pm 0.39$ & $10.24 \pm 0.61$ & $26.2 \pm 3.84$ \\
\hline Andhrapradesh & 5 & $2.86 \pm 0.50$ & $11.4 \pm 0.22$ & $25.15 \pm 4.69$ \\
\hline Karnataka & 21 & $2.72 \pm 0.47$ & $10.35 \pm 0.69$ & $26.33 \pm 4.44$ \\
\hline
\end{tabular}

The ANOVA test had shown that the ICD and OCD significantly varied between regions with ( $p$ value -0.006 for ICD and 0.039 for OCD) (Table IV).

Table IV: Showing values for ICD,OCD AND Canthal index between states

\begin{tabular}{|l|c|c|}
\hline Variable & F & P value \\
\hline ICD & 4.336 & 0.006 \\
\hline OCD & 2.845 & 0.039 \\
\hline Canthal Index & 0.760 & 0.518 \\
\hline
\end{tabular}

\section{Discussion}

The dimensions of face and proportions of its components vary in different ethnic groups ${ }^{[7]}$. Ethnicity of South Indian population belongs to Dravidian ethnic group. Dravidians are one of the non-Aryan races of Southeast Asia and are distributed mainly in South India and Ceylon ${ }^{[8]}$. Intercanthal distance is influenced by the shape of face,race and gender ${ }^{[9]}$.Inner intercanthal distance serves as a guide to estimate width of maxillary central incisors, which is a determinant of facial aesthetics $^{[10]}$.

LeTT et al reported that facial profile can vary in different ethnic groups and that the dominant characteristics of the Asian faces were a wider ICD in relation to shorter palpebral fissures compared to Caucasians ${ }^{[11]}$. Normal values of inner and outer canthal distances, canthal index serves as useful parameters in the evaluation and treatment of congenital or post traumatic deformities of the cephalic and facial regions such as telecanthus, occular hypotelorism and craniosynostosis.

Laestadiusreported that in $78 \%$ of adults, the ICD is attained by the age of 1 year, after which the growth in this area is slow in contrast to outer orbital dimension ${ }^{[12]}$. According to Epker and Fish, these values are established by $6-8$ years of age and do not change significantly after this time. This stable landmark can be identified, located and measured accurately ${ }^{[13]}$.
Vasanthakumar et al did their study in Malaysian South Indian ethnic adults and found that the outercanthal distance was $97.15 \mathrm{~mm}$ in males and 91.78 $\mathrm{mm}$ in females which was lower than present study. And they also noted intercanthal distance and canthal index to be $34.1 \mathrm{~mm}$ and 35.22 in males; and $32.77 \mathrm{~mm}$ and 35.86 in females respectively. These values are very high compared to the values of present study. They have observed sexual dimorphism in all parameters whereas in the present study there is significant sexual dimorphism in intercanthal distance only[14].

The values of inner intercanthal distance found in present study was lower than the normative value found by Farkas et al for Indian population. At the sametime, the outercanthal distance was higher than that given by Farkas et $\mathrm{al}^{[15]}$. Our study showed the lower innercanthal distance and higher outercanthal distance than that found by Singh J.R. et al ${ }^{[16]}$, Agarwal ${ }^{[17]}$ for Indian population but our study coincides with the findings of Gupta et $\mathrm{al}^{[18]}$. The present study showed mean inner intercanthal distance as $2.55 \pm 0.51 \mathrm{~cm}$ which is low compared to that reported by Harinee ${ }^{[19]}$ in her study on Kanyakumari population (Part of Tamilnadu, South India) which is $3.275 \pm 0.254 \mathrm{~cm}$ whereas mean outer canthal distance coincides with her study value.

\section{CONCLUSION}

The present study which is done on 200 participants of age 18-25 years showed low value for inner intercanthal distance and high outercanthal distance for South Indian population than Indian population as such. This data values will serve as important aiding tool in recostructive cosmetic surgeries,for diagnosing dysmorphic syndrome by genetic counsellors and for identifying dead or live person by forensic experts.

\section{Conflict of Interest: Nil}

Source of Funding: Self funding. 
Ethical Clearance: Ethical clearance from the institutional ethical committee obtained for the study

\section{References}

1. P. Vasanthakumar, Pramod Kumar, Mohandas Rao. Anthropometric Analysis of Palpebral fissure dimensions and its position in South Indian Ethnic Adults. Oman Med J 2013;28 (1):26-32.

2. Adhikari N, Ambekar MN, KC S. An anthropometric comparison of inner canthal distance, outer canthal distance and canthal index in the Indian and Nepalese undergraduate students of Nepalgunj Medical College. J Nepal Med Coll. 2016;14(2):12-4

3. Torres-Restrepo et al.: Agreement between cranial and facial classification through clinical observation and anthropometric measurement among envigado school children. BMC Oral Health 2014 14:50.

4. E. A. Osunwoke, A. Elekwa, I. F. Bob-Manuel and S. O. Ojeka. A Study On The Normal Values of Inner Canthal,Outer Canthal, Canthal Index, Interpupillary Distance And Head Circumference of 23 - 42 Years Igbos.Global Journal of Medical Sciences Vol 9, No. 1 \& 2, 2010: 43-48.

5. Dr. Bipana Manandhar. Study of Canthal Index among Students of Dental College .JNDA | Vol. 19 No. 2

6. Sadacharan CM. Orbitofacial assessment of Indian Americans and its significance-an anthropometric study. MOJ Anat Physiol. 2015;1(4):85-89. DOI: 10.15406/mojap. 2015.01.00018“

7. Wu KH, Tsai FJ, Li TC, Tsai CH, Peng CT, Wang TR. Normal values of inner canthal distance, inter pupillary distance and palpebral fissure length in normal Chinese children in Taiwan. Acta Paediatr Taiwan 2000;41:22-7.

8. George $\mathrm{S}$, Bhat $\mathrm{V}$. Inner canthal distance and goldenproportion as predictors of maxillary central incisor width in south Indian population. Indian J Dent Res 2010;21:491-5.

9. Blumenfeld J. Racial identification in the skull and teeth. The University of Western Ontario Journal of Anthropology. 2000; 8(1):22-6.
10. Rehulina Ginting, Dennis and Navashangkari Ravichandran. Comparison of the golden proportion value between the width of maxillary central incisors with the innercanthal distance of Malaysian Indians using golden mean gauge. International Journal of Applied Dental Sciences 2017; 3(2): 141-143

11. Le TT, Farkas LG, Ngim RC, Levin LS, Forrest CR. Proportionality in Asian and North American Caucasian faces using neoclassical facial canons as criteria.Aesthetic Plast Surg. 2002; 26(1):67

12. Laestadius ND, Aase JM, Smith DW. Normal inner canthal and outer orbital dimensions. J Pediatr 1969;74:465-8.

13. Bruce HE, Leward CF. Dento facial deformities. Integr Orthod Surg Correct 1999;1:10-2.

14. Vasanthakumar P, Kumar, Mohandas Rao KG. Photogrammetric analysis of palpebral fissure dimensions and its position in Malaysian South Indian Ethnic adults by gender.North Am J Med Sci 2012;4:458-62.

15. Leslie G. Farkas, Marko J. Katic, BA,Christopher R. Forrest. International Anthropometric Study of Facial Morphology in Various Ethnic Groups/ Races. The Journal of Craniofacial Surgery/ Volume 16, Number 4 July 2005.

16. Singh JR, Banerjee S. Normal values for interpupillary, inner canthal and outercanthal distances in an Indian population. Hum Hered 1983;33:326-8.

17. Agrawal J, Yogesh AS, Shukla CK, Banerjee C, Chandrakar AK. Orbitofacial anthropometric assessment of inter-canthal and outercanthal distance measurement in Chhattisgarh region. Biomed Res- India 2013 Volume 24 Issue 3

18. Gupta VP, Sodhi PK, Pandey RM. Normal values for intercanthal, interpupillary and outer intercanthal distances in the Indian population. Int J clinc Pract 2003; 57(1): 25-9.

19. Harinee. T, Orbitofacial Anthropometric Assessment of Inner-Intercanthal and OuterIntercanthal Distance in Kanyakumari Populationan Invivo Study" http://repository-tnmgrmu. ac.in/9902 